\title{
As concepções de masculino e masculinidade consoante Freud e sua consideração a partir da escuta de homens penectomizados devido a câncer
}

\section{Conceptions of masculine and masculineness according to Freud and considerations from the hearing of men who underwent penectomy due to cancer}

\author{
Luciano Lima de Oliveira* \\ Hospital Universitário Walter Cantídio - HUWC, Fortaleza, Ceará, Brasil \\ Laéria Fontenele** \\ Universidade Federal do Ceará - UFC, Fortaleza, Ceará, Brasil
}

\begin{abstract}
RESUMO
O tema do masculino e da masculinidade é recorrente na fala dos homens penectomizados por câncer de pênis sobre os quais recaiu nossa pesquisa de pós-graduação. Nesse contexto deparamos o refinamento com que Freud aborda ambos os conceitos. Pretendemos com esse artigo, sistematizar tais concepções na obra de Freud. Para tanto, realizamos uma exegese dos principais textos em que deles se ocupou. Partimos da premissa de que masculino e masculinidade não se confundem, embora estejam inegavelmente articulados. Procuraremos mostrar que enquanto o primeiro diz respeito à dinâmica pulsional, o segundo se refere à escolha de uma posição sexuada ao final do Complexo de Édipo. Tal escolha diz respeito menos à divisão entre dois sexos que entre duas modalidades de posicionamento perante o falo e o objeto causa do desejo. Além disso, trabalhamos a especificidade do desejo masculino, principalmente no que concerne à dissociação entre amor e desejo.
\end{abstract}

Palavras-chave: Masculino, Masculinidade, Sexualidade, Pulsão

\begin{abstract}
The theme of masculine and masculineness is recurrent in the speech of men who underwent penectomy due to cancer of the penis, these men being the subject of our post-graduate research. It is in this environment that we ran into Freud's fine approach to both concepts. It is our aim with this article to order systematically those concepts from Freud's work. To this end, we developed an exegetical work involving the main texts in which he deals with the theme. We start from the premise that masculine and masculineness are two separate concepts although they are articulated very clearly. We tried to show that while the former is related to sex drive dynamics, the latter refers to a choice of a sexual positioning at the end of the Oedipus complex. Such a choice refers less to the separation of two sexes than to two kinds of positioning in face of the phallus and the object that causes desire. Besides, we worked details of male desire, especially those related to the dissociation between love and desire.
\end{abstract}


Keywords: Masculine, Masculineness, Sexuality, Drive.

\section{Considerações iniciais}

Empreendemos recentemente uma pesquisa acerca dos impactos acarretados pela amputação cirúrgica do pênis (penectomia) por câncer peniano na sexualidade masculina. Nesse contexto fomos conduzidos a refletir acerca da relação estabelecida entre "ter" o pênis e a identidade viril, tal como nos revelam alguns homens de nosso universo de pesquisa.

A citada pesquisa surgiu das inquietações experimentadas pelo primeiro autor desse artigo em sua prática clínico-hospitalar para com homens acometidos por câncer de pênis, submetidos à penectomia total ou parcial, bem como das questões que foram tendo lugar no processo de supervisão conduzida pelo segundo autor, que participou nessa condição como orientadora da pesquisa por nós desenvolvida junto a um programa de Pós-Graduação inserido numa universidade pública brasileira. Uma das questões que se nos apresentaram foi a existência de uma dissimetria entre o discurso desses homens e aquele sustentado pela medicina e pela psico-oncologia e que serve de parâmetro para as intervenções terapêuticas póscirúrgicas, o qual é centrado, sobretudo, no funcionamento sexual amparado na anatomia e fisiologia. Essa discordância nos despertou o desejo de problematizar a aludida dissimetria em uma pesquisa de mestrado, tendo em vista as possibilidades de favorecer em nosso trabalho, junto a essa equipe, uma maior coerência entre o acompanhamento desses pacientes e suas experiências para com esse dano real sofrido. Nosso objetivo geral foi investigar o impacto da penectomia na sexualidade masculina; e os específicos, identificar possíveis saídas encontradas pelo sujeito para a satisfação pulsional na ausência do pênis e verificar os destinos desse impacto em relação aos pontos de ancoragem da virilidade, além de seus respectivos deslocamentos. Para tanto, procuramos, na medida do possível, escutar esses homens a partir da técnica analítica, abstendo-nos de dirigirmos suas falas, embora não se tratasse estritamente de uma psicanálise. Destarte, procuramos estabelecer uma maior coerência entre a nossa pesquisa e a clínica psicanalítica, espaço privilegiado da pesquisa em psicanálise no sentido que Ihe é dado por Freud e Lacan. Escutamos seis sujeitos, por ocasião de suas revisões pós-cirúrgicas, oriundos do Serviço de Urologia do Hospital do Câncer do Ceará - ICC. O tempo decorrido desde a cirurgia até o encontro conosco variou de dez meses a três anos, e a média de idade das pessoas atendidas foi de 60,5 anos. Após cada encontro, as falas dos sujeitos foram anotadas e, posteriormente, relatadas sob a forma de vinheta clinica. Assim, mantivemo-nos fiéis aos significantes por eles produzidos, inerentes às suas subjetividades e não a um saber prévio a elas. Quanto aos 
resultados obtidos, destacamos: a dissociação entre amor e desejo presente na vida amorosa dos sujeitos pesquisados; o confronto com a tarefa de reconstruir a imagem viril, perante a mulher e os outros homens, sem o sustentáculo imaginário fornecido pela anatomia; a tendência de elaborar o sem sentido da doença e da cirurgia atribuindoas ao exercício da virilidade junto a outras mulheres, que não a esposa; e a ausência de "vida sexual" para os que ainda possuem o coto peniano, contrariando o que preconiza o saber médico quanto à capacidade de gozo sexual dos pacientes parcialmente penectomizados. Concluímos que através de uma escuta psicanalítica foi possível perceber que, no discurso desses sujeitos, a sexualidade se mostra, de certo modo, refratária aos modelos reabilitadores restritos à dimensão funcional da sexualidade e, portanto, redutíveis ao comportamento dos mesmos quando do ato sexual. Isso evidenciou a relevância de um trabalho mais abrangente para com eles, não restrito a intervenções pedagógicas, com o intuito de fazer com que eles elaborem a perda sofrida e possam lidar de forma simbólica com a sua nova realidade, inclusive corporal.

Observamos que, para esses homens, até o momento da realização da cirurgia, a dimensão simbólica inerente ao saber construído em torno do real da diferença dos sexos não podia prescindir da condição imaginária, cujo sustentáculo é o pênis. Após a amputação, o reencontro desses homens com a dimensão traumática da sexualidade impõe a cada um deles a reconstrução de sua condição viril, agora sem o suporte imaginário do pênis.

Um daqueles a que nosso estudo se refere lembra que, pouco tempo após a cirurgia, o cirurgião foi visitá-lo e disse-lhe: "Quando fui operá-lo, disse-lhe que você iria ficar o mesmo homem", para logo em seguida pedir confirmação: "E aí, você ficou o mesmo homem?". Ele, um tanto constrangido, responde ao médico: "É doutor [...] Fiquei o mesmo homem, mas não sou homem pra mulher".

Outro sujeito afirma que se considera "um homem morto", pois para ele um homem se define pela possibilidade de gozar sexualmente com várias mulheres. Além disso, para ser, como ele diz, "um homem que nasceu para ser homem", deve se limitar à penetração no ato sexual. Fazer sexo oral não é coisa de homem, uma vez que, segundo sua fala, o de que uma mulher gosta mesmo é de pênis.

Vimos insinuar-se na fala desses sujeitos uma articulação entre "ser homem" e poder responder, por meio de seu pênis, ao que quer a mulher no encontro sexual. A cópula desempenha para eles um papel significativo na afirmação da imagem viril. A penectomia os conduz à tarefa de encontrar novas respostas para o querer feminino. Assim, consideramos ser possível pensar, para esses homens, o masculino e a masculinidade em sua relação com suas vidas amorosas, pois é nesse contexto que eles, conforme indicado em seus dizeres, esperam da mulher o reconhecimento de sua virilidade. 
Diante da necessidade dessa articulação, fomos levados a circunscrever a dificuldade de se definir o masculino, assim como o feminino, em Freud, além de algumas peculiaridades do desejo masculino, trabalhadas por ele e retomadas por Lacan a partir dos avanços que este promoveu acerca da concepção de falo. É do resultado de parte desse empreendimento que nos ocuparemos nesse artigo.

\section{Masculino não é sinônimo de masculinidade}

É importante ressaltar que masculino e masculinidade -, assim como feminino e feminilidade - não são tomados aqui como sinônimos. Freud, em alguns textos, não parece diferenciá-los nitidamente, embora a articulação por ele estabelecida entre ambos e a teorização acerca do Édipo e da Pulsão nos permita relacionar o termo masculino com uma das polaridades em jogo na satisfação pulsional, tais como sujeito-objeto, ativo-passivo, fálico-castrado e masculino-feminino, conforme Freud (1923a[1989]); ao passo que "masculinidade" ou "virilidade" diz respeito ao processo identificatório resultante do Complexo de Édipo, que permite ao homem situar-se na cultura. Consideramos necessário fazer tal distinção para que se sublinhe a complexidade e imprevisibilidade - como alertou Freud - inerentes à subjetivação do sexo anatômico. Ainda que nosso objetivo seja discutir a problemática do masculino, o feminino não pode deixar de comparecer, uma vez que ambos, como veremos, não são tomados por como qualificativos de gênero - como em outros saberes -, mas por polaridades relativas aos modos de satisfação pulsional. Esse par de opostos é indissociável da concepção de bissexualidade psíquica dos seres humanos, tal como Freud a desenvolveu a partir de 1905.

Uma das primeiras manifestações do interesse de Freud acerca do masculino e do feminino surge no contexto de sua correspondência com Fliess, precisamente nas ideias que apresentavam à reflexão, um do outro, relativas ao tema da bissexualidade. Fliess acreditava ser todo Homem biologicamente bissexual, e que tal constituição compreendia a luta entre representações típicas de ambos os sexos em um mesmo indivíduo. (FREUD, 1887-1904 [1986]). Em relação a isso, André (1991), considera que a teoria da bissexualidade de Fliess sustentava tanto a simetria entre duas metades, cada uma contendo a outra na condição de recalcado, quanto o princípio da periodicidade de uma substância sexual que levaria ao acasalamento e à reprodução. Observa-se aí uma concepção puramente biológica do recalque, ponto de radical discordância por parte de Freud.

A concepção de uma bissexualidade biológica leva os psiquiatras de então a relacionarem o homossexualismo à influência maior ou menor de componentes masculinos e femininos nas tendências psíquicas e 
nas escolhas objetais do indivíduo. Freud refuta tais teorias, valendose de sua escuta clínica, a qual Ihe mostrava que a escolha de objeto não era fruto de uma determinação instintual pré-determinada. Nesse contexto, o conceito de pulsão surge como operador metapsicológico das observações clínicas de Freud a respeito da bissexualidade:

Ello nos prescribe que debemos aflojar, en nuestra concepción, los lazos entre pulsión y objeto. Probablemente. La pulsion sexual es al comezo independiente de su objeto, y tampoco debe su genesis su origen a los encantos de este. (FREUD, 1905[1989], p. 134).

Conceber o masculino e o feminino sem nenhuma relação apriorística com o objeto, portanto para além de qualquer pré-determinação biológica, permite significativos avanços na investigação Freudiana sobre a sexualidade. Nesse sentido, são esclarecedoras as palavras de Jorge (2007, p.40):

A pulsão é a resposta conceitual forjada por Freud para dar uma consistência às observações trazidas por diferentes autores da época sobre a bissexualidade. Freud jamais deixaria de falar em bissexualidade até o final de sua obra, e a definiu em sua relação com a escolha de objeto, descartando toda e qualquer referência à bissexualidade biológica, tal como a sustentava Fliess.

Para estabelecer com precisão o que vem a ser o feminino e o masculino para a psicanálise em sua diferença com outros campos do saber e com o senso comum, Freud (1905[1989], p.200) diz-nos em uma nota de 1915:

Es indispensable dejar en claro que los conceptos de "masculino" y "femenino", cuyo contenido que tan unívocos parecen a la opinión corriente, en la ciencia se cuentan entre los más confusos y deben descomponerse al menos, en tres direcciones. Se los emplea en el sentido de actividad y pasividad, o en un sentido biológico, o en el sociológico. El primero de estos tres significados es el esencial, y el que casi siempre se aplica en el psicoanálisis.

Vemos, assim, masculino e feminino serem tomados em referência à atividade e à passividade; o masculino correspondendo à primeira e o feminino à segunda. Não se trata, pois, da divisão no mesmo indivíduo entre caracteres do sexo masculino e do sexo feminino, mas de uma polaridade que diz respeito à finalidade pulsional, ou, em outros termos, à gramática da pulsão. Desse modo, masculino e feminino passam a ser considerados elementos importantes para a apresentação dos sintomas e das fantasias do neurótico, uma vez que 
constituem formas de satisfação da pulsão, tanto ativas quanto passivas.

É o que é sublinhado por Freud (1908[1989]) em “Fantasias histericas y su relacion con la bissexualidad". A disposição bissexual do indivíduo aparece de modo cristalino nas fantasias dessa neurose. Freud chama atenção para o fato da investigação psicanalítica do sintoma histérico apontar o papel desempenhado, em sua composição, pelas fantasias masculinas e femininas. Há, pois, aí a presença de finalidades pulsionais de caráter ativo e passivo, como no exemplo que Freud fornece da mulher que com uma mão segura o vestido contra o corpo, ocupando o lugar de objeto de uma agressão sexual, e com a outra sinaliza querer se livrar da roupa, identificando-se com o agressor.

Ao abordar esse mesmo assunto, Assoun (2006, p.38) chama a atenção para o caráter volátil do par ativo/passivo como versão do masculino e do feminino, mas observa que é através dele que a "'doutrina da bissexualidade' começa a encontrar sua conexão com a "doutrina pulsional". Podemos pensar, então, que as exigências de esforço que a pulsão faz à alma resultam na realização de um trabalho do aparelho psíquico que tem o propósito de oferecer saídas para os empecilhos que se apresentam à satisfação pulsional. Tais saídas resultam na ocupação, pelo neurótico, de uma posição masculina ou feminina na fantasia. A passagem do verbo da voz ativa para a passiva corresponderia ao deslocamento do masculino ao feminino. No entanto, em "Pulsões e destinos da pulsão" (1915[2004b]), Freud adverte que a finalidade ativa da pulsão nunca é totalmente transformada em passividade.

A problemática do masculino e do feminino, tal como Freud a aborda, demonstra que a relação entre os dois é menos de exclusão que de combinação. Isso nos possibilita pensar que um mesmo indivíduo pode ocupar uma posição masculina frente a um objeto e feminina em relação a outro; ou até questionarmos se, em relação ao mesmo objeto, determinado sujeito não poderia transitar de uma posição masculina a uma feminina e vice-versa.

Sobre isso há elucidativas passagens em dois textos de Freud: a primeira em "La sexualidad femenina" (1931[1989]), no qual ele afirma que o trânsito da passividade para a atividade é um fato inerente à vida anímica. Segundo ele, entretanto, a passagem da passividade para a atividade não acontece do mesmo modo, com a mesma eficácia, para todos e que dessa variabilidade "se puede extraer uma inferencia acerca de la intensidad relativa de la masculinidad y femenidad que habrá de mostrar en su sexualidad" (p. 238). A segunda passagem, a encontramos em La feminidad (1933[1989], p.106): “Decimos, entonces que un ser humano, sea macho o hembra, se comporta en este punto masculina y en estotro y femeninamente". 
Para ilustrar as complicações derivadas da combinatória atividade/passividade, reportaremo-nos agora a algumas considerações que Freud faz em "De La historia de una neurosis infantil (el "Hombre de los Lobos")" (1914 [1989]), "Pegan a un niño" (1919 [1989]) e em "Sobre la psicogénesis de un caso de homosexualidad femenina" (1920 [1989]).

No primeiro texto, Freud se depara com as variações que a finalidade pulsional pode alcançar e os deslocamentos que o indivíduo deverá realizar sobre a polaridade ativo/passivo para dar conta das exigências de satisfação libidinal. Tais variações têm lugar na fantasia e acabam se manifestando na relação objetal.

Assim, vemos o homem dos lobos ocupando, por um lado, uma posição passiva frente às investidas sedutoras da irmã. Entretanto, por outra feita, Freud chama a atenção para alguns sonhos produzidos pelo paciente, cujo conteúdo revela fantasias nas quais ele assume uma atitude ativa em relação a ela (desejo de desnudála, tocá-la). Num momento logicamente segundo, as reprimendas da irmã, relativas à atitude ativa que o paciente lhe dirigia, levam-no a buscar ativamente a se colocar numa posição passiva, agora em relação à babá. Busca ativa de uma satisfação passiva, que implicava seduzir a babá para que ela Ihe tocasse o pênis. Confrontado com as recusas e admoestações daquela, sua libido regrediu ao estádio analsádico ao mesmo tempo em que se volta para a figura paterna. 0 paciente esperava conseguir do pai a satisfação sexual passiva que Ihe fora negada pelos dois objetos precedentes. No entanto, surge um elemento novo, relativamente à finalidade pulsional. Ao regredir ao estádio anal-sádico, é sob o modo do sadismo dirigido aos animais e de uma hiperatividade para com os empregados da casa que ele buscará junto ao pai a satisfação sexual, sob o modo masoquista, mas não feminina, pois que ativa (ASSOUN, 2006).

Freud observa que, a partir do sonho com os lobos, essa dinâmica sofrerá a influência de um elemento decisivo à polaridade ativo/passivo e sua correspondência com o masculino e o feminino: a angústia de castração.

O sonho com os lobos, segundo Freud, evoca a cena primária em que o paciente testemunha a relação sexual dos pais. Tal evocação teria, posteriormente, confrontando o sujeito com o desejo de assumir o lugar da mãe no coito, servindo de objeto à satisfação sexual do pai. Aqui, a posição seria passiva, mas agora associada ao feminino, isto é, ao castrado. Percebemos que Freud prefere falar, nesse contexto, em masculino e feminino com relação à castração, reservando a polaridade ativo/passivo às organizações pré-genitais da libido. Identificar-se com a mãe, ocupando lugar de objeto sexual para o pai, equivalem na fantasia a ser castrado, perder o pênis, isto é, deixar-se feminilizar pelo pai. Tal desejo cai sob o golpe do recalque, 
mas, obviamente, permanece ativo no inconsciente, dando ocasião para que ressurja sob a forma sintomática da fobia de lobos.

Uma observação a ser levada em conta a partir da leitura do Homem dos Lobos é que a satisfação pulsional, em relação ao mesmo objeto, pode ser buscada ora de modo ativo, ora de modo passivo; que frente a diferentes objetos, o sujeito pode ocupar uma posição masculina para alguns e feminina para outros.

No segundo texto, Pegan a un niño, Freud (1919[1989]), acentua a pertinência de se abordar masculino e feminino com relação à fantasia. Freud dirige a atenção do leitor para a intervenção da diferença sexual na fantasia, no que tange aos desejos incestuosos voltados ao pai. Observa-se, novamente, os deslocamentos do sujeito em torno do masculino e do feminino, bem como sua combinação com os modos de satisfação libidinal sadismo e masoquismo.

No caso do menino, este ocupa na fantasia, que chega à consciência, um lugar passivo em relação à mãe, que se encontra no lugar de sujeito. Freud observa que o recalque incide sobre o desejo de se fazer bater pelo pai. Ao que parece, não é tanto a finalidade passiva da pulsão que provoca o recalque no menino, mas ser passivo para o pai. Prova disso é que na passagem à consciência o trabalho psíquico consiste em trocar a pessoa e o sexo do sujeito da fantasia. Tal singularidade está diretamente ligada ao fato do pai ser para o menino o agente da castração. Atente-se para o fato, já sublinhado, de que masculino e feminino não guardam uma relação necessária nem com a escolha de objeto, nem com o que culturalmente se convenciona designar por masculinidade e feminilidade.

\section{Masculino, masculinidade e escolha de objeto}

O terceiro texto a que fizemos referência versa sobre os atendimentos que Freud (1920[1989]) prestou a uma jovem homossexual. Nele, o tema principal é a dinâmica da escolha de objeto e a sua relação com o masculino e o feminino. Freud faz referência à bissexualidade psíquica dos seres humanos para lançar luz sobre a confluência de desejos homossexuais e heterossexuais sobre um mesmo objeto. Além disso, adverte que a pertença de um indivíduo a um ou outro sexo é função do arranjo combinatório de três elementos: características sexuais físicas, modo de satisfação pulsional (ativo/passivo) e escolha objetal. O mais importante, a nosso ver, é o fato de Freud estabelecer com clareza a independência entre esses três elementos.

Para iniciar a análise do referido caso, Freud apresenta ao leitor duas interrogações, cujo conteúdo já havia sido discutido nos "Tres ensayos de teoria sexual" (1905 [1989]): (1) A homossexualidade da paciente era tributária da dominância de caracteres sexuais 
somáticos do sexo masculino? (2) Tratava-se de uma homossexualidade congênita ou adquirida?

Freud sublinha que a paciente possuía características físicas predominantemente femininas, embora algumas estivessem mais próximas do que se costumava atribuir à masculinidade, como a alta estatura e traços fisionômicos mais enérgicos que suave, acrescentando-se a isso características intelectuais masculinas como inteligência aguda e fria clareza de pensamento. O hermafroditismo somático, Freud mais uma vez esclarece, não pode responder pelo homossexualismo, ainda que não possa ser de todo negligenciado. Como ele observa, a combinação de caracteres somáticos existe em qualquer ser humano, portanto também nos heterossexuais. De todo modo, ele é categórico ao afirmar que a correlação que se tenta fazer entre características somáticas ou cognitivas e o sexo do indivíduo são na verdade convenções, tendo, pois, pouco valor científico:

Más importante, sin duda, es que en su conducta hacia su objeto de amor la circunstancia de haber adoptado la muchacha, para con el objeto de su amor había adoptado en todo el tipo un tipo, vale decir, la humildad y la enorme sobrestimación sexual que es propia del varón amante, la renuncia a toda satisfacción narcisista, la preferencia por amar antes que ser amado. Por tanto, no sólo había elegido un objeto femenino; tambem había adoptado hacia él una actitud masculina (FREUD, 1920[1989], p. 148).

A citação acima nos convida a interrogar o que seria essa "atitude masculina" diante do objeto. Para tanto, nos serão bastante profícuas as considerações de Freud em três textos essenciais a essa problemática: "Sobre un tipo especial de la elección de objeto en el hombre" (1910 [1989]), "Sobre una degradación general de la vida erótica" (1912 [1989]), e "À guisa de introdução ao narcisismo" (1914 [2004a]). Ressaltamos que nos limitaremos a extrair dos aludidos trabalhos apenas o que julgarmos pertinente à proposta desse estudo.

No primeiro trabalho, Freud se detém sobre um tipo de escolha de objeto frequentemente observada nos homens e que é composta pela presença de quatro "condições eróticas": (1) O terceiro lesado, (2) o caráter leviano da mulher, (3) supervalorização das mulheres cujo comportamento sexual se aproxima da prostituição e (4) intenção redentora. As duas primeiras se referem às exigências dirigidas ao objeto e as duas últimas à conduta do amante.

Para o homem, cuja escolha de objeto está em conformidade com a primeira condição, a mulher só pode despertar o desejo se estiver comprometida, isto é, se houver um outro que ocupe o lugar de legítimo possuidor do objeto. O que parece pesar aqui não é tanto os atributos físicos do objeto, mas sua referência a um terceiro. Daí 
Freud observar que mesmo as mulheres antes indiferentes ou desprezadas por um homem podem passar a serem objetos de seu investimento libidinal tão logo estabeleçam laços amorosos com outro homem.

O terceiro lesado ocupa na fantasia o lugar do pai, e as mulheres são tão insubstituíveis e valorizadas quanto mais a libido do homem encontra nelas traços maternos. A fidelidade de que fala Freud, ainda que pareça paradoxal relativamente à constante substituição das mulheres na vida erótica do homem, é perfeitamente compatível com tal sucessão, uma vez que, por um lado, trata-se de uma fidelidade à mãe, representada na fantasia pelos traços maternos que cada uma das mulheres sinaliza portar.

Em relação à segunda condição - o caráter leviano da mulher -, a escolha recairia sobre mulheres cuja fidelidade estivesse sempre sob suspeita, podendo variar desde aquela casada disponível ao flerte às adeptas da poligamia. Vê-se que também aqui existe a presença do terceiro, ainda que os ciúmes do amante - elemento decisivo para a valorização da mulher - não lhe digam respeito como "possuidor legal" da mulher, mas a outros com os quais ela trave relações. Nas palavras de Freud: "En los casos mas acusados, el amante no muestra ningún deseo de posee para sí solo a la mujer, y parece sentirse enteramente cómodo dentro da la relación triangular" (1910[1989], p.161].

A reativação de desejos infantis relativos à mãe e do ódio dirigido ao pai, com os quais o menino estava ocupado no drama edípico, poderiam explicar a exigência de leviandade do objeto como condição erótica, isto é, a mãe surge aí, graças ao modo de funcionamento do inconsciente, como prostituta, uma vez que realiza os mesmos atos que aquela. O pai, por seu turno, ressurge como aquele a quem a mãe satisfaz sexualmente, e a frustração dos desejos edipianos do sujeito o levam a situar, em sua fantasia, a mãe como uma mulher infiel. É assim que Freud tenta explicar o mecanismo da segunda condição erótica supracitada.

No que concerne à terceira condição, o amante supervaloriza as mulheres cuja conduta sexual é duvidosa, reprovável ou que se entregam à prostituição. A libido é intensamente dirigida a tais objetos, passando a um segundo plano tudo o que não lhes disser respeito. Juram fidelidade absoluta e a conduta assume um caráter obsessivo, ainda que Freud ressalve que em certa medida tal característica esteja presente sempre que alguém se apaixona.

Por fim, a última condição - a intenção redentora - implica o desejo de salvar a dama de sua marginalização moral. O homem se acredita, assim, necessário à redenção moral da mulher. Contudo, faz-se importante ressaltar que não é preciso que ela esteja numa condição degradante em relações aos valores sociais para que tal conduta salvadora se estabeleça. Freud assinala que para manter sua fantasia 
os amantes desse tipo não podem abandonar sua amada, não importa o que aconteça.

Qual seria, pois, a origem do tipo de escolha objetal a que as quatro condições acima mencionadas se referem? Freud adverte o leitor de que a diversidade relativa às condições eróticas dos homens que se alinham ao tipo de escolha acima descrito não deve ser buscada em múltiplas fontes. Existe um ponto em comum, que possibilita entendê-las como produto de um mesmo processo psíquico:

\begin{abstract}
Esa elección de objeto de curioso imperio y esa rara conducta tienen el mismo origen psíquico que en la vida amorosa de las personas normales; brotan de la fijación infantil de la ternura a la madre y constituyen uno de los desenlaces de esa fijación. [...] en nuestro tipo ella (la líbido) se ha demorado tanto tiempo junto a la madre, aun después de sobrevenida la pubertad, que los objetos de amor elegidos después llevam el sello de los caracteres maternos y todos devienen unos subrogados de la madre fácilmente reconocibles (FREUD, 1910 [1989], p.162).
\end{abstract}

A origem do tipo de escolha de objeto que Freud encontra no homem e qualifica de masculino, está inextricavelmente relacionada ao Complexo de Édipo, expressão que surge pela primeira vez exatamente no texto em discussão.

O segundo trabalho de Freud (1912[1989]) acerca da atitude masculina frente ao objeto utiliza como balizador da discussão o tema da impotência psíquica. Freud procura articular a impossibilidade de realização do ato sexual às peculiaridades da escolha de objeto, marcada pela dissociação entre amor e desejo. Com efeito, nos homens que padecem de impotência psíquica, os órgãos genitais permanecem anatômica e fisiologicamente normais, assim como o desejo sexual. Não há comprometimento orgânico de espécie alguma. Freud acentuará, aí, que a impotência não se dá em relação a qualquer mulher, levando a crer que certas qualidades do objeto estão implicadas na falha da potência viril. Dizer que tal fenômeno se deve às características do objeto não deve ser entendido como falta de habilidades ou de atributos sexuais daquele. Trata-se, nesse caso, de algo inerente à dinâmica do desejo do próprio homem do que das características do objeto em si.

Se na vida erótica, dita normal, a constituição do objeto compreende a confluência das correntes psíquicas carinhosa e sexual, pode-se pensar que no que diz respeito à impotência houve dissociação ao invés de combinação entre ambas. É em torno da dinâmica dessas formas de investimento libidinal que Freud concentrará seus esforços para dar à impotência psíquica alguma inteligibilidade.

As duas correntes estão presentes na determinação dos investimentos que o menino realiza sobre os objetos e que Freud 
denomina "escolha primaria de objeto infantil". Durante o período de latência é a corrente carinhosa que tende a predominar, haja vista que nesse intervalo irão ser erigidas as barreiras contra o incesto, organizadas pelo complexo de Édipo. Com a chegada da puberdade, a pulsão sexual reivindica uma participação mais ampla no investimento libidinal e sua primeira providência é investir nos objetos primários. Como o rapaz, por essa época, já foi marcado pelo complexo de castração o caminho regressivo da libido até as figuras parentais encontra-se interditado, levando-a a ter que se dirigir a outros objetos. Freud pondera, no texto em apreço, que mesmo esses novos objetos são escolhidos tendo como protótipo as imagos parentais. Assim, as duas correntes, carinhosa e sensual se fundem sobre o objeto escolhido, o qual será tanto mais valorizado psiquicamente quanto maior for o investimento da pulsão sexual dirigido até ele.

Exposto, portanto, o caminho considerado normal por Freud para a consecução da vida sexual, trata-se de verificar que tipo de fator interveniente poderia provocar uma alteração capaz de facilitar o surgimento de uma impotência.

Freud afirma que quando o objeto é inacessível e/ou a atração exercida pelos objetos escolhidos na infância assume uma magnitude suficiente para mobilizar a libido, esta se afasta da realidade e a vida sexual do indivíduo passa a se concentrar na fantasia, na qual predomina o investimento nos objetos sexuais primários, fruto da fixação libidinal sobre eles. Mesmo que, por meio da substituição das figuras parentais por outros objetos, as fantasias venham a se tornar conscientes, como no caso da masturbação, a libido permanece ligada aos objetos que deveria abandonar. E assim é porque no inconsciente a substituição não elimina o que foi substituído; sua função é, ao contrário, assegurar a este último acesso à consciência através de seus derivados.

A impotência psíquica se articula, então, a uma impossibilidade para o homem de dirigir a pulsão sexual até mulheres que possuam traços dos objetos incestuosos, reservando para elas a corrente carinhosa, cujo fim sexual está ausente. Tal dissociação é resumida por Freud nos seguintes termos:

La vida amorosa de estos seres permanece escindida en dos direcciones, que El arte ha personificado como amor celestial y terreno (o animal). Quando aman no anhelan, y quando anhelan no pueden amar. Buscan objetos a los que no necesitan amar, a fin de mantener alejada su sensualidad de los objetos amados [...] (FREUD, 1912[1989], p. 176).

Para tais homens, a solução encontrada para não cair na impotência psíquica seria o rebaixamento do objeto sexual. Degradando-o em 
sua fantasia, aproximam a mãe da prostituta e, com isso, podem desejá-la sem o peso da interdição do incesto.

Freud chega à conclusão de que a impotência psíquica está presente, de um modo ou de outro, de forma mais ou menos pronunciada, na vida erótica do homem civilizado. Para ele, apenas uma minoria consegue fazer coincidir as duas correntes sobre o mesmo objeto. Para o homem, pois, o respeito à mulher acaba por ser um estorvo à sua potência sexual, já que por conta dele não julga conveniente dirigir à mulher amada os componentes perversos da pulsão sexual. Freud assinala que a fim de ser feliz na vida sexual, o homem precisa superar o respeito à mulher e a fantasia de incesto com a figura materna. De certo modo, superar o respeito pela mulher implica não supervalorizá-la, destinando-lhe uma grande quantidade de libido objetal em detrimento da libido do eu, conforme Freud (1914[2004a]).

Com efeito, a temática da escolha de objeto constitui para Freud uma das melhores formas de investigar o narcisismo. Haveria dois tipos de escolha objetal possíveis e que estariam disponíveis tanto para homens quanto para mulheres: a forma anaclítica e a forma narcisista. Grosso modo, temos que a primeira elege como objeto as figuras parentais ou seus substitutos, através do apoio nas pulsões de autoconservação; enquanto a segunda, ao invés de ter na imagem da mãe a matriz de suas escolhas objetais ulteriores, toma como referência o próprio eu do sujeito.

Apesar de observar que os dois tipos de escolha aplicam-se a todos os indivíduos, Freud afirma que há diferenças importantes entre homens e mulheres. Na vida erótica daqueles predominaria o tipo anaclítico, o amor completo ao objeto e sua consequente supervalorização, à custa do eu. Quanto à mulher, o modo de escolha de objeto que Freud (1914[2004a], p.108) qualifica de "o mais frequente e provavelmente o mais puro e autêntico", implica o narcisismo original, "desfavorável à estruturação de um amor objetal regular, caracterizado pela supervalorização do objeto sexual. [...] Elas não têm necessidade de amar, mas de ser amadas, e estão dispostas a aceitar o homem que preencher essa condição" (p.108).

Percebemos, nessas breves passagens, que masculino e feminino, mesmo em relação à escolha de objeto, não podem ser pensados como adjetivos correspondentes a homem e mulher respectivamente. Freud diz que no homem predomina o tipo de escolha anaclítica e na mulher o tipo narcisista, embora admita haver mulheres que amam segundo o "tipo masculino", dirigindo ao objeto a supervalorização característica daquela modalidade. Assim, se há mulheres que amam "anacliticamente", masculino e feminino são usados, nesse texto, como posições a serem ocupadas tanto por homens quanto por mulheres. O que Freud chama de tipo masculino de escolha objetal 
não é, como também se depreende do texto sobre o narcisismo, função da anatomia sexual dos homens.

O que todos os trabalhos até aqui comentados parecem deixar claro é que as posições masculina e feminina desempenham para Freud o papel de valiosos instrumentos de investigação acerca da dinâmica pulsional e da vida erótica dos indivíduos. Ainda que ele deixe clara sua insatisfação com a associação entre masculino e atividade, bem como feminino e passividade, Assoun (2006, p. 38) observa que “hablar en términos de 'activo' e 'pasivo' es el único medio de no callarse cuando se quiere abordar 'psicológicamente' lo masculino y lo femenino, es decir dar cabida a su inscripción psíquica". É, pois, como ativo e passivo que masculino e feminino serão inscritos no psiquismo, participando da dinâmica edípica, através da qual a construção da masculinidade será levada a efeito.

A partir do complexo de Édipo, abre-se para ambos os sexos uma combinatória complexa no que diz respeito à masculinidade, à feminilidade, ao masculino e ao feminino, tanto em relação à dinâmica pulsional quanto à escolha de objeto. Um trecho de "Sobre la psicogénesis de un caso de homosexualidad femenina", dá-nos uma ideia de tal variação:

[...] Un hombre con cualidades predominantemente viriles, y que exhiba también el tipo masculino de vida amorosa, puede, con todo eso, ser un invertido con relación al objeto, amar sólo a hombres, no a mujeres. Un hombre en cuyo carácter prevalezcan de llamativa las cualidades femeninas, y aun que se porte en el amor como una mujer, en virtud de esa actitud femenina debéria estar destinado al varón como objeto de amor; no obstante, muy a pesar de eso, puede ser heterosexual y no mostrar hacia al objeto una inversión mayor que una persona normal media el corrientemente normal (FREUD, 1920 [1989], p.162).

Temos, pois, que um homem com "qualidades masculinas" pode preservar sua masculinidade e o tipo masculino de amor escolhendo como objeto outro homem, ao invés de uma mulher. Por outro lado, um homem que possua "qualidades femininas" e adote para com 0 objeto uma forma de amor feminina, nem por isso pode deixar de ser definido como heterossexual, pois mesmo amando como as mulheres é sobre estas, e não sobre os homens, que recai sua escolha objetal. Como pensar essa intrincada rede de possibilidades a partir do complexo de Édipo? A tarefa não é simples e para efeito de concisão de nosso estudo, nos limitaremos ao Édipo no menino. Trata-se de tentar abordar o masculino e a masculinidade em referência à castração e aos amores edípicos.

Freud (1938/1940 [1989]) nos diz que o primeiro objeto sexual do menino é a mãe. É ela que lhe dispensa os cuidados à preservação da vida e ao mesmo tempo Ihe sexualiza o corpo, transformando-o em 
zona erógena. A maternagem oferece as condições para que a mãe se apresente como primeiro e mais significativo objeto da libido. Aqui a posição do menino é passiva frente aos sedutores cuidados maternos. Quando o menino descobre o pênis enquanto zona erógena, infere que ele ocupa um lugar de importância para a mãe. Suas investigações na esfera sexual o levam a fantasiar que pode obter prazer com o pênis junto à mãe, através de manobras de sedução, de uma atitude ativa, masculina. Vê-se, assim, o menino passando de seduzido a sedutor. O pai, que até então era também objeto amado, surge agora como rival a ser batido.

Devemos lembrar, conforme Freud (1923[1989]), que entre as personagens envolvidas no Complexo de Édipo é tecida uma rede de relações, posições subjetivas e modalidades de investimento libidinal que não se resume ao esquema reduzido do Édipo positivo: o menino ama a mãe e tem para com o pai uma atitude ambivalente, prevalecendo, no caso da saída normal, a identificação ao pai como pressuposto da masculinidade. Freud observa que a bissexualidade psíquica da criança, leva a que o menino também adote uma atitude amorosa passiva frente ao pai, reservando à mãe hostilidade e ciúmes. Vemos que a construção da masculinidade, pois, não é algo tão simples. Ela é o resultado da resolução do complexo de Édipo e da consequente localização do homem na cultura. Tal exige, como condição, que o menino abandone a posição passiva de ser amado pelo pai em favor da identificação com ele. O elemento decisivo a toda esse processo é a angústia de castração.

Frente à ameaça de castração, de perda do pênis, a posição masculina, ativa do menino, que até então era expressa por suas tentativas de possuir a mãe e sua atitude ambivalente em relação ao pai, se torna intimidada, inibida. Entre perder o pênis e renunciar ao objeto materno, o interesse narcísico prevalece na manutenção do órgão. Freud (1938-1940[1989]) nos diz que, nesse momento do drama edipiano, se o componente feminino da bissexualidade do menino for por demais intenso encontrará a oportunidade para se fazer predominante na vida pulsional. Desse modo, o menino poderia se instalar numa posição passiva em relação ao pai. Contudo, isso não significa que a masculinidade estará ameaçada, pois o menino segue identificando-se à figura paterna em suas fantasias masturbatórias. O investimento libidinal dirigido à mãe também é preservado, favorecendo a escolha de objeto heterossexual, ainda que ocupando na fantasia uma posição passiva frente à mulher:

Como resto de la fijación erótica a la madre, suele establecerse una hipertrófica dependencia de ella, que se prolongará más tarde como servidumbre hacia la mujer. Ya no osa amar a la madre, pero no puede arriesgarse no ser amado por ella, pues así correría el peligro de ser denunciado 
por ella al padre y quedar expuesto a la castración (FREUD, 1938-1940[1989], p.190).

Em termos sintéticos, podemos depreender da discussão que nos ocupa, que enquanto formas de satisfação pulsional - articuladas no contexto do complexo de Édipo pela angústia de castração -, as posições masculina e feminina, por si só, não decidem a escolha de objeto ou a conquista da masculinidade. No que diz respeito à vida erótica, as atitudes masculinas e femininas estão presentes, combinadas, no modo como o sujeito se dirige ao objeto.

Uma vez traçadas e discutidas as questões pertinentes ao masculino e à masculinidade tal como Freud as concebe, pensamos ser oportuno refletirmos, ainda, embora que pontualmente, sobre o lugar que a anatomia ocupa nas considerações freudianas sobre o tema em questão, o qual nos interessa de perto devido à sua implicação com o assunto de nossa pesquisa acerca dos impactos provocados pela penectomia na sexualidade masculina.

Em primeiro lugar, pensamos que se Freud não abandona de todo a anatomia genital como referente da diferença sexual é porque, inapelavelmente, a definição do sexo masculino é função da presença do pênis. Por essa razão Freud (1930[1989], p. 103), nos lembra que "es la Anatomia, y no la Psicología, la que puede registrar el carácter de lo masculino y lo femenino". No entanto, são as consequências psíquicas da diferença anatômica que decidirão, ou não, a filiação do sujeito ao seu sexo biológico. A declaração de sexo que o sujeito deverá fazer está relacionada não com a disposição anatômica fornecida pela natureza, mas, primordialmente, com aquilo que Freud chamou de "organização genital infantil":

En el carácter principal de esta organización genital infantil es, al mismo tiempo, su diferencia de la organización genital definitiva del adulto. Reside en que, para ambos os sexos, solo desempeña un papel un genital, el masculino. Por tanto, no hay un primado genital, sino un primado del falo (FREUD, 1923[1989], p.146).

Se Freud fala que não há uma primazia do genital e sim uma primazia do falo é porque pênis e falo não são sinônimos, embora não se possa negar que o primeiro seja o suporte imaginário do segundo. Assim, a diferença sexual para Freud não tem como referente 0 pênis, órgão genital, mas o falo como reportando-se à falta de objeto, ou seja à oposição entre fálico e castrado que remete ao fato de que na edificação de nosso psiquismo ele é tomado como premissa universal. O falo, ainda, pode ser referenciado como aquilo que sublinha a dificuldade do ser falante quanto à subjetivação diferença sexual. O falo enquanto representante simbólico do pênis que, num primeiro momento é tomado como premissa universal, e num 
segundo tempo falta à mãe, momento decisivo que corresponde no menino ao surgimento da angústia de castração. Esta é uma importante consequência psíquica da diferença sexual anatômica, e que influenciará, conforme Freud (1925[1989]), a divergência entre o desenvolvimento sexual masculino e feminino. A angústia de castração sinaliza o declínio do complexo de Édipo no menino, ocasião em que a assunção ou não da masculinidade será decidida.

\section{Considerações finais}

Conforme apontado ao princípio desse artigo, a necessidade de definirmos e diferenciarmos os termos masculino e masculinidade está diretamente relacionada com a dissimetria de posições teóricas e clínicas que costumam balizar o acompanhamento pré e pós-cirúrgico da equipe que presta assistência médica e psicológica a homens sujeitos à penectomia. Em geral, a ênfase dada, nesse acompanhamento, por médicos, enfermeiros e psicólogos, numa concepção funcionalista e biológica da sexualidade, bem como a incidência de valores morais que circulam e são transmitidos em nossa cultura acerca da masculinidade podem trazer obstáculos ao trabalho do psicanalista junto a essa equipe; ou mesmo tornar difícil a sua colaboração para a promoção do avanço clínico do trabalho da equipe multidisciplinar na qual está inserido, no sentido de ampliar e evidenciar as questões que emergem de seu trabalho de escuta com esses homens, concernentes à subjetividade dos mesmos. Tal escuta mostrou o quanto se faz necessário nos reportarmos à forma pela qual a penectomia se reflete tanto no modo como eles concebem sua masculinidade, quanto na maneira pela qual se relacionam com seus parceiros sexuais. Nos dizeres desses homens, vimos a presença de um trabalho de elaboração psíquica do impacto provocado pela doença e pelo trauma decorrente da perda total ou parcial do pênis. Este trabalho, consoante nossas constatações, ocorreu mediante a rearticulação dos personagens representativos da pulsão, próprios à edificação do saber inconsciente. Tal rearranjo significante se impõe na medida em que a intervenção no real do corpo desses sujeitos atualiza importantes questões que estão na base de suas estruturações psíquicas e que remetem à questão da diferença sexual e da castração resultante da trajetória edípica. No desencadeamento desse processo psíquico de elaboração, observamos o lugar ocupado por diversos aspectos da trajetória dos referidos sujeitos, tais como: o adiamento da busca pelo tratamento ou a procura pelo médico quando este pouco pode fazer para salvar o pênis; a reorganização da imagem do corpo próprio e da imagem viril; a dinâmica da vida amorosa e o direcionamento dado à pulsão sexual frente à 
impossibilidade ou à restrição do ato sexual decorrentes do ato cirúrgico.

Podemos ainda constatar que a imagem viril dos sujeitos foi construída em torno de representações imaginárias envolvendo a posse e o uso do pênis; de ser capaz de fazer uma mulher gozar tão somente com o órgão peniano, denunciando a crença de que o gozo feminino é, como o masculino, restrito ao órgão. As pulsões parciais não encontram lugar na construção do que eles consideram ser homem, e por isso os sujeitos passam a empregar parte de sua energia psíquica na tarefa de manter os representantes das aludidas pulsões suprimidos. Lembramos que, por exemplo, para um dos sujeitos escutados, J.F.S., é preferível ficar em casa na companhia dos filhos, a ter que masturbar uma mulher, seja com a língua, seja com o dedo, pois tal vai de encontro à imagem viril que tanto preservou junto às mulheres e aos amigos.

Outro aspecto importante foi a nossa constatação de que a cirurgia provoca, nos referidos sujeitos, o confronto com uma falta de sentido relativa à representação que mantinham de sua autoimagem masculina, junto ao Outro, levando-os a ter que buscar novos significantes para reconstruir o dano simbólico aí implicado. É um pouco o que alguns dos sujeitos nos mostram quando se remetem aos significantes com os quais buscam se identificar após a cirurgia. Isso nos adverte quanto à pertinência de abordar esses pacientes de forma a facilitarmos o trabalho psíquico, sempre singular, de elaboração da amputação, ao invés de oferecer-lhes nossos próprios significantes.

Outro ponto que fomos levados a considerar diz respeito à estreita articulação existente entre a imagem viril e a dissociação entre amor e desejo, que observamos existir na vida dos homens sujeitos à penectomia. Para alguns deles, ser homem é ter mais de uma mulher, não restringir seu gozo à figura da esposa, a quem dedicam seu amor. No entanto, para grande parte dos sujeitos, a impossibilidade de fazer convergir sobre o mesmo objeto o amor e o desejo responde pela perda do pênis como uma espécie de punição que o Outro the dirige. Desse modo, observamos que a etiologia do câncer e a perda do órgão para esses sujeitos não se dobra ao saber médico e psico-oncológico. A culpa presente em suas falas aponta, antes, para uma tentativa de dar sentido ao dano imaginário e simbólico que sofreram.

Culpa e desejo são elementos observáveis no discurso desses homens. Ao contrário do que sugerem alguns autores, os sujeitos indicam que o desejo não se mantém somente pela presença dos testículos, mas da fantasia que cada um articula para dar conta das exigências pulsionais. O que alguns sujeitos mostram é uma permanente tentativa de recalcar o desejo, associado à perda do pênis. 
Sobre a importância de se levar em conta a fantasia na elaboração psíquica da perda total ou parcial do pênis, chamamos atenção para o fato de que a ausência total do pênis não é impedimento para o encontro sexual, ainda que focalizado na região genital, conforme um dos pacientes revelou.

Por outro lado, a associação entre vida sexual e tamanho do coto peniano, foco de muitos estudos nessa área, deve ser relativizada de acordo com o que nos dizem os sujeitos parcialmente penectomizados. À exceção de R.I., todos os demais que se submeteram à penectomia parcial se abstiveram de relações sexuais. Assim, ainda que para o discurso médico o exercício da sexualidade possa estar garantido nos casos de penectomia parcial, observamos que para os sujeitos a ela submetidos, a vida sexual ainda não pôde ser retomada. O que percebemos, quanto a isso, foi, ao contrário do que prescreve o discurso da reabilitação, que esses homens resistem a deslocar a libido para outras partes do corpo, seja do seu ou do corpo do parceiro. Freud (1905[1981], p. 1184) sublinha que as circunstâncias, sejam externas ou internas:

[...] dificultan o alejan la consecución del fin sexual normal (impotencia, custo elevado del objeto sexual, peligros del acto sexual) favorecen [...] la tendencia a permanecer en los actos preparativos, convirtiéndolos en nuevos fines sexuales que pueden sustituirse al normal.

Sobre isso, devemos dizer que, embora a penectomia bem possa ser adicionada ao conjunto das circunstâncias acima referidas, não observamos, nos sujeitos desta pesquisa, a tendência de que nos fala Freud. Mesmo para aqueles que perderam parte do pênis - os quais, segundo a medicina, ainda estão aptos ao coito - observamos que o gozo do órgão ainda não é possível, talvez por que ainda precisem reinvestir libidinalmente esse "pedaço" que sobrou. Desse modo, os sujeitos da pesquisa nos lembram de que, para além do órgão anatômico, aquilo que perderam tem a ver com o atributo fálico, 0 qual, a partir da posse e uso do pênis, acreditavam possuir perante 0 Outro. Dessa forma, os mesmos tentam dar conta das exigências pulsionais através de significantes destinados a restaurar os danos imaginários e simbólicos, provocados pela cirurgia. Assim, a imagem viril, por exemplo, tende a ser reconstruída em torno da ocupação de outros lugares frente ao desejo do Outro, como o de pai, o de protetor da esposa, o de provedor da família, o de trabalhador honesto e exemplar, entre outros. Para quase todos os sujeitos, então, o trabalho, mesmo o doméstico, e a vida familiar passam a constituir os trilhos por onde a satisfação pulsional persegue seu sempre inapreensível objeto.

Essa impossibilidade estrutural, relativa à colagem entre pulsão e objeto, caracteriza o humano e a sexualidade. Se para os homens 
penectomizados, a vida sexual continua a se apoiar, de certa forma, na genitalidade, seja no encontro com a mulher, seja somente no devaneio - o que os leva a compartilhar de uma concepção acerca da sexualidade bastante familiar aos discursos votados à reabilitação sexual - ainda assim tal sexualidade se revela eminentemente psíquica, avessa à estereotipia instintual.

Acreditamos que é exatamente nessa sexualidade psíquica, organizada pela fantasia inconsciente, que residiria a inadequação do sujeito ao saber que fundamenta as prescrições da medicina e da psico-oncologia acerca do que seria uma vida sexual compatível com a nova realidade daquele. Tal discrepância, bastante comum e fonte de surpresa para a ordem médica, não parece estar associada à falta de conhecimento sobre a sexualidade e sobre o corpo; de acompanhamento psicológico antes ou após a cirurgia para o paciente e seu parceiro ou de sentimentos de vergonha relacionados ao tamanho do pênis ou ausência da glande, mas ao saber inconsciente que marca a singularidade de cada um.

Por fim, devemos ressaltar que por operar a partir de um não-saber, dando espaço para a fantasia inconsciente do sujeito, o analista pode contribuir para ampliar a discussão acerca da repercussão da penectomia para a sexualidade masculina. No entanto, tal somente será factível se o analista, ainda que inserido em equipes multidisciplinares, preservar a radicalidade do que Freud descobriu e Lacan formalizou: que com ou sem pênis, não há relação sexual.

\section{Referências}

ANDRÉ, S. O que quer uma mulher? Rio de Janeiro: Jorge Zahar Editor, 1991.

ASSOUN, P. L. Introdução à epistemologia freudiana. Rio de Janeiro: I mago, 1983.

Metapsicologia freudiana: uma introdução. Rio de Janeiro: Jorge Zahar Ed., 1996.

Lecciones psicoanalíticas sobre masculino y femenino.

1. ed. Buenos Aires: Nueva Visión, 2006.

FREUD, S. A correspondência completa de Sigmund Freud para Wilhelm Fliess (1887-1904), Editado por Jeffrey Masson. Rio de Janeiro, I mago, 1986.

. Tres ensayos para una teoria sexual (1905). In:

Obras Completas. Buenos Aires: Amorrortu Editores, 1989. Tres ensayos para una teoria sexual (1905). In:

Obras Completas. 4.ed. Madrid: Biblioteca Nueva, 1981. Tomo II. - Fantasias histericas y su relación con la bissexualidad (1908). In: Obras Completas. Buenos Aires: Amorrortu Editores, 1989. 
(1910). In:

Sobre un tipo especial de la elección de objeto en el hombre Editores, $198 \overline{9}$.

Sobre una degradación general de la vida erótica (1912). In:

Obras Completas. Buenos Aires: Amorrortu Editores, 1989.

Historia de una neurosis infantil (Caso del "Hombre de los

lobos") (1914). In:

Obras Completas. Buenos Aires: Amorrortu Editores, 1989.

À guisa de introdução ao narcisismo (1914). In:

Escritos sobre a psicologia do inconsciente. Coordenação geral da tradução: Luiz Alberto Hans. Rio de janeiro: Imago, 2004a. Volume 1.

. Pulsões e destinos da Pulsão (1915). In: Escritos

sobre a psicologia do inconsciente. Coordenação geral da tradução: Luiz Alberto Hans. Rio de Janeiro: Imago, 2004b. Volume 1.

. Pegan a un niño (1919). In:

Obras Completas.

Buenos Aires: Amorrortu Editores, 1989.

Sobre la psicogénesis de un caso de homosexualidad femenina (1920). In: Amorrortu Editores, $198 \overline{9}$.

. La organización genital infantil (1923a). Adición a la teoría sexual. In: Obras Completas. Buenos Aires: Amorrortu Editores, 1989.

. El yo y el ello (1923b). In:

Buenos Aires: Amorrortu Editores, 1989.

Obras Completas.

- Algunas consecuencias psíquicas de la diferencia sexual anatómica (1925). In: Obras Completas. Buenos Aires: Amorrortu Editores, 1989.

. El malestar en la cultura (1930). In: Obras Completas. Buenos Aires: Amorrortu Editores, 1989. . Esquema del psicoanálisis (1938-1940). In: Obras Completas. Buenos Aires: Amorrortu Editores, 1989. . Sobre la sexualidad femenina (1931). In: Obras

Completas. Buenos Aires: Amorrortu Editores, 1989.

JORGE, M. A. C. A teoria da sexualidade de Freud 100 anos depois. Psyche, São Paulo, v.11, n. 20, p.29-46, jun. 2007. Disponível em: http: //pepsic.bvspsi.org.br/scielo.php?script=sci_arttext\&pid=S14151 $1382007000100003 \&$ lng =en\&nrm=iso >. Acesso em: 18 out. 2009.

\section{Endereço para correspondência}

Luciano Lima de Oliveira

Rua Capitão Francisco Pedro, 1290, Rodolfo Teófilo, CEP 60430-370, Fortaleza, Ceará, Brasil.

Endereço eletrônico: lucianoldeoliveira@yahoo.com.br

Laéria Fontenele 
Avenida da Universidade, 2662, Bloco Didático Profo ícaro de Sousa Moreira(Laboratório de Psicanálise), Benfica, CEP 60020-180, Fortaleza, Ceará, Brasil.

Endereço eletrônico: laeria@terra.com.br

Recebido em: 31/03/2011

Reformulado em: 16/08/2011

Aceito para publicação em: 18/11/2011

Acompanhamento do processo editorial: Ana Maria Lopez Calvo de Feijoo

\section{Notas}

* Psicanalista. Mestre em Psicologia pela Universidade Federal do Ceará (UFC). Psicólogo do Hospital Universitário Walter Cantídio (UFC).

** Psicanalista. Professora Adjunta do Mestrado e da Graduação em Psicologia da UFC. Coordenadora do Laboratório de Psicanálise da UFC e Diretora do Corpo Freudiano - Escola de Psicanálise. Seção Fortaleza. 